\title{
Giacomo Barozzi Da Vignola \\ Canon of the Five Orders of Architecture \\ Branko Mitrović, translation and commentary \\ New York: Acanthus Press, 1999
}

Reviewed by Stephen R. Wassell

In the recent Polifilo edition of Vignola's highly influential and crucially important treatise, Regola delli cinque ordini d'architettura, eight English translations are listed in the chronology of previous editions (“Cronologia della edizioni”) [Casotti 1985: 527-577]. This chronology does not include Branko Mitrovićs new English translation and commentary, which is the subject of the present review. In reviewing Mitrović's translation and commentary, it is illuminating to compare his approach to that of his predecessors. To do this, I shall briefly survey the various English translations, a survey which as far as I know does not exist elsewhere, while highlighting three areas: the motivation of the translators, their intended audience, and the extent to which each attempted to be literal to Vignola's original text. Then I shall focus on the approach of the translators to perhaps the most challenging of Vignola's descriptions: that of the constructions concerning the entasis of columns. This will provide a sort of litmus test to compare the different translations. Of course, in order to fully appreciate the worth of Mitrović's new work, one must focus largely on his thorough and insightful commentary. It will become clear that English speaking architects and architectural historians now have access to an accurate and essential new aid in designing, analyzing, and appreciating classical architecture.

\section{A survey of the English translations of the Canon}

The first English version of Vignola was translated and published by Joseph Moxon in London in 1655. His motivation is obvious; as he states in his preface, "To the Ingenious Artist":

there [are] few Nations of any note, that have not his Works translated into their own language: only we here in England (I know not whether it be through carelesness [sic] in Artists, or else covetousness) mind not those things which makes [sic] other Countries (that have nothing else to boast of) so famous among their neighbours [Moxon 1655]. 
As for his approach to Vignola's original text, he explicitly states in his preface, "To the Reader":

In the Translation of this Book I have followed (so near as I could) the words of our Author, unlesse [sic] here and there I have been a little more large, thereby endeavoring the better to expresse [sic] his meaning, and instruct the young Practitioner [Moxon 1655].

In this last passage, and in other places in the preface, which includes a glossary of terms, Moxon makes it clear that he directs his translation for those not already expert in the subject of architecture.

A second, competing translation was done by John Leeke, first published in 1669, also in London. In his "Translator's Preface", Leeke writes that he styles Vignola as,

The Regular Architect, because he sets down one general Rule for the Principal Numbers of all the Five Orders; which Rule our Author found from the Observation which he made of the Antiquities of Rome [Leeke 1669].

On the title page, Leeke calls himself a "student of the mathematicks [sic]", and he indicates that his translation is

... for the use and benefit of Free Masons, carpenters, joyners [sic], carvers, painters, bricklayers, plaisterers [sic]: in general for all ingenious persons that are concerned in the famous art of building [Leeke 1669].

Leeke's motivation was presumably to produce a superior translation; certainly, his illustrations are much closer to the originals than are Moxon's. As with Moxon, Leeke explicitly comments in the "Translator's Preface" on his desire to be as true as possible to Vignola:

The Author being perspicuous of himself, we have endeavoured to render him in his own Sense, only adding here and there a word upon occasion, to explain his meaning more fully [Leeke 1669].

Unlike Moxon, Leeke explicitly states on his title page that his translation is "rendered into English from the original Italian”.

The Polifilo edition lists two English translations of the Canon published in the 18th century. The first, published in London in 1703, appearing in combination with a translation of Perrault's Vitruvius, is essentially a fifth edition of Moxon's translation [Boyer and Moxon 1703]. The second, published in London in 1761 by Robert Sayer, is really a substantially different treatise from Vignola's, albeit based on the Canon [Sayer 1761]. It offers entirely different illustrations and text than the original.

Over a century passed before the next English translation was published in Boston in 1889. Tommaso Juglaris and Warren Locke offer the following in their prefatory "Translators' Advertisement": 
People of the schools, the professions, and the building trades have long been conscious of the fact that an American translation of this standard work would meet a necessity felt by all. The subscribers place this translation before the public with a feeling of having supplied the want. Great care has been taken to have only the best illustrations of the five Orders, and to describe them carefully in terse English [Juglaris and Locke 1889]

This makes their motivation and intended audience clear. As for their treatment of Vignola's original text, they actually refer to Vignola in the third person, rather than using his first person approach, in their translation. It seems that their intention is to remain true to Vignola's meaning without being as concerned with his exact wording.

Two more English translations of the Canon were published in 1891, both in the United States. One by Arthur Lyman Tuckerman, published in New York, was intended "for the use of the art schools of the Metropolitan Museum of Art" [Tuckerman 1891:3]. It is clear from the preface and introduction that Tuckerman's motivation is to help carry on the classical tradition during a time when it had been "assailed repeatedly" [Tuckerman 1891: 7]. He states:

A knowledge of the details of the orders, the proportioning of dimensions, the spacing of columns and imposts is in itself a large portion of the designer's stock in trade; that is to say of the education indispensable to him [Tuckerman 1891: 10].

In the "Publisher's Note" it is stated that "these plates are taken from various foreign publications, chiefly Leveil's edition of Vignola" [Tuckerman 1891: 3]. Unfortunately, the French version on which this translation is based strays considerably from the original Italian [Leveil 1857].

The other translation published in 1891 is also based on the French version by J. A. Leveil with engravings by A. Hibon. Translator T. R. Kimball offers the following in the Preface:

The recent appearance of an American edition of Vignola, together with the fact that there has already been circulated one feeble English version of that invaluable work, has prompted this translation, the object of which... is to supply the demand for an English Vignola by giving to the standard edition what is called for, i.e., English notes, and thus prevent its being superseded by an imitation and an inferior one. In translating, it has been intended to give the exact sense of the French, rather than to cling to a literal transcription of words. When from peculiarities in the structure of the language it is impossible to find English equivalents, the literal translation is adhered to. ... If explanations, etc., given as translator's notes strike any reader as too obvious, let him remember that Vignola is not only the Bible, but the primer of the architectural student [Kimball 1891].

It is noteworthy that the footnotes include comparisons to Palladio's work, albeit a limited number.

Those familiar with The American Vignola, a quite successful text by William R. Ware first 
published in New York in 1901, may find it surprising that it is listed in the Polifilo chronology as an English edition of the Canon. As was the 1761 Sayer work described above, though based largely on Vignola's ideas, The American Vignola is a substantially different treatise [Ware 1901].

The penultimate English translation, drawn and arranged by Pierre Esquié, translated by William Robert Powell, includes the following in the Preface:

Several years ago a translated edition was published of the J. A. Leveil Vignola for student use. That edition is out of print and the present revised book is based on it. Much of the data of the former edition has been condensed and many new plates added. The text of the present edition gives as near as possible, the exact sense of the French, but is not a literal translation. All of the text and notions of value to the student have been translated and supplemented with a glossary and foot notes. This is essential in that Vignola is the primer of the architectural student [Esquié and Powell 1921].

It is not surprising, then, that this translation reads very similarly to the last; in fact, many any of the notes are based directly on Kimball's.

Turning to the English translation now under review, Mitrović makes his motivation, intended audience, and approach to Vignola's original text quite clear in his extensive preface and introduction. Regarding his motivation, Mitrović states:

I perceive the publication of Vignola's work as part of a wide effort, shared by many friends and colleagues, to recover the forgotten knowledge of building classically. At the same time I have undertaken the work on the translation and commentary of Vignola's Canon for a number of theoretical reasons that I gradually came to be aware of over a period of almost fifteen years [Mitrović 1999: 11).

Mitrović describes the influence of Rudolf Wittkower's classic Architectural Principles in the Age of Humanism on himself and on his profession; after Wittkower, many embraced the idea that the underlying proportions of the elements of classical architecture, including the components of the orders, were at the heart of its beauty. However, many modernists used these same ideas to reject the use of the orders as superfluous ornament, unnecessary to the expression of the underlying proportions. Mitrović explains that he also started to realize that meaning-based interpretations of the orders - whether they be musical (e.g., Wittkower's "harmonic proportions"), anthropomorphic (e.g., the association of column shape with the human body), or even architectonic (e.g., the identification of triglyphs with beams protruding from the entablature) - was of little use in teaching students how to use the orders. He became increasingly attracted to the formalism of Vignola's treatment of the orders: "[I]n Vignola's straightforward concern for shapes I saw the theoretical purity that our contemporary architectural writings so often lack" [Mitrović 1999: 13].

Mitrović views his text primarily as a practical guide for architects and, especially, for students of architecture. Mitrović's approach to Vignola's original text goes hand in hand with his intended audience: 
The public for which this book is intended also determined many of the solutions I adopted for the translation. When I was confronted with the choice between the more literal or scholarly rendering of the text or the version that would be easier to follow and use in everyday architectural practice, I opted for the latter. I have not even attempted to convert Vignola's style into English his long sentences are hardly enjoyable to read in Italian and in English they are incomprehensible [Mitrović 1999: 16].

Although he allows himself to employ a liberal translation of Vignola where the original is "unclear, vague, or insufficient to understand his drawings" [Mitrović 1999: 16], Mitrović does maintain Vignola's first person and gives the reader the sense of what a modern, Englishspeaking Vignola might produce. Moreover, Mitrović saves his explanations of Vignola's word choices or geometric constructions for the footnotes. I find his overall approach quite successful.

It should be noted that Mitrović has chosen to use the second edition of Vignola's treatise (1572) rather than the first (1562) in order to include the somewhat controversial "wellknown plate in which the five orders are mutually compared" [Mitrović 1999: 15] (Figure 1). In his introduction he provides a brief description of the research behind the authenticity of this plate. Here he also comments on his intentions regarding his commentary; I shall save this until the last part of this review.

\section{The entasis "litmus test"}

Let us now compare Mitrović's treatment of Vignola's constructions for the entasis of columns with those of the other translators (Figure 2). There are three constructions given.

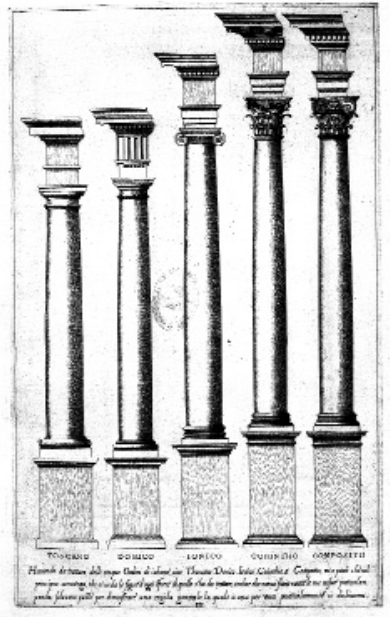

Figure 1

"The System of the Orders." Plate 3 from Giacomo Barozzi Da Vignola, Canon of the Five Orders of Architecture. Branko Mitrović, translation and commentary. (New York: Acanthus Press, 1999). Reproduced by permission.

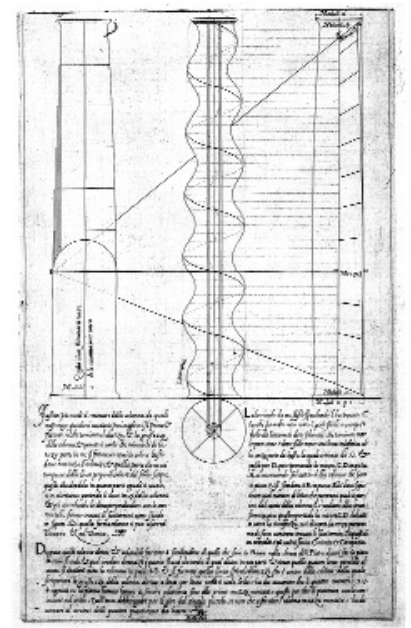

Figure 2

"Entasis." Plate 31 from Giacomo Barozzi $\mathrm{Da}$ Vignola, Canon of the Five Orders of Architecture. Branko Mitrović, translation and commentary. (New York: Acanthus Press, 1999). Reproduced by permission. 
Vignola presents the "first and best known" (Plate 31), which I shall refer to as the standard method for entasis, for use with the Tuscan and Doric orders. The second construction is one of Vignola's own invention, which he prefers with the Ionic, Corinthian, and Composite orders. The third is his construction for spiral columns such as those in the church of St. Peter in Rome; though this is not literally entasis, I include it here for completeness.

Moxon splits Vignola's original illustration into two drawings. The first shows the standard approach, while the second shows the method of Vignola's invention as well as his spiral column construction. The first construction is actually quite simple, but Moxon's verbose ("large", as he puts it) text complicates matters. Moxon's painful translation is of little help in explaining Vignola's own method for entasis, and his instructions for spiral columns are even worse. It does not help that the second of Moxon's drawings is quite a simplified version of the original.

If Moxon's description of entasis is too verbose, Leeke's suffers from the opposite problem. Like Vignola, Leeke combines all of the entasis constructions into one illustration and describes them rather tersely. Leeke's text is fine for the standard, simple approach to entasis, but in each of the more complicated constructions, his text consists of one long and confusing sentence that sacrifices clarity for the sake of remaining true to Vignola's description.

The two 18th century translations need not be analyzed: again, one is essentially a fifth edition of the Moxon translation, and the Sayer edition, which is not truly a translation of the Canon, does not even include the entasis constructions.

The 1891 translation by Juglaris and Locke does not include the spiral column construction and thus avoids the most complex of the descriptions. Their description of the standard construction for entasis is fine, but their description of Vignola's own construction is seriously flawed. They simplify it by assigning a fixed distance in number of column diameters between two points, $D$ and $E$. Unfortunately, this is simply incorrect: Vignola's method for defining point $E$ is completely different, and moreover, their choice ignores the fact that there are different (column) height to diameter ratios for the different orders.

The discussion of entasis methods in Tuckerman's 1891 translation of Leveil's Vignola is quite brief. While this is not a problem with the standard method, Vignola's own method and the method for constructing spiral columns suffer from the brevity, especially in the latter case. The Kimball translation of Leveil is a slight improvement. It offers a fairly readable and accurate description of the two methods for constructing entasis of columns, but the description of the spiral construction is still somewhat vague. To be fair, Vignola's original text concerning the spiral construction is rather lacking (more on this below). But rather than use the footnotes to clarify matters, Kimball offers the reader such information as:

It may be well to note that "entasis" is in this country commonly and incorrectly used for "diminution". It should never be used other than for "swelling". ... The good taste of entasizing columns has been questioned, on the ground of interference with the perfectly structural composition belonging to an element entirely utilitarian in its functions. [Kimball 1891: Plate 60]

The Powell translation of Esquiés Vignola, having been based on Kimball's translation of Leveil, is essentially the same; in fact, the footnotes to the entasis descriptions are identical. It 
should be noted that, in all three of these translations of the Canon based on Leveil's edition, the drawing for the spiral column is inaccurate where the spiral approaches both the base and the capital, which is precisely where Vignola's original text is most confusing. As for Ware's The American Vignola, column entasis is used throughout the drawings of the text, but no discussion of its correct construction is given.

Mitrović's translation comprises the best solution. He supplies a quality reproduction of the entasis illustration from Vignola's 1572 edition. (To be fair, this uses technology that has become routine only in recent years.) He carefully translates Vignola's original text without being slavish to the awkward style of the original. Finally, Mitrović uses the footnotes not for commentary (which he saves for his introductory and concluding passages) but rather to clarify the confusing aspects of Vignola's description. While the standard method is simple enough to understand from the original without further explanation, Mitrović offers several short notes explaining Vignola's own method for entasis. As for the spiral column construction, Mitrović provides a 2-paragraph note, starting with a fair criticism: "Vignola's account here is cryptic, incomplete, and his drawing not as precise as it should be" (Plate 31). He goes on to clarify the construction thoroughly yet succinctly, focusing the most attention on the most difficult aspect, namely where the spiral approaches the base and the capital. Mitrović is the clear winner of the entasis litmus test!

\section{Mitrovićs commentary}

Of course, the real gem of Mitrović's Canon is his commentary. It is well organized, with commentary on the various plates grouped by topic; for example, the section entitled "Intercolumniation" refers to plates 4-6, 10-11,15-17, and 21-23. Mitrović provides a wealth of information, of which I shall give an overview momentarily. The commentary itself is thoroughly footnoted, providing quite a reference list for further study.

This first section of the commentary, entitled "Vignola's Introduction", starts with a brief history of Vignola's ouevre and the impact of his treatise. Mitrović then explains:

The main intention of this commentary is to explain the contemporary context of Vignola's theory of the classical orders - not so much in order to explore the lines of influence (which would be a scholarly undertaking and of little value to practicing architects) but rather to clarify how much and in which points Vignola's position differed from those of other Renaissance theorists [Mitrović 1999: 88].

In so doing, Mitrović "offer[s] a general survey of sixteenth-century theories of orders..." [Mitrović 1999: 88]. This will be explored further below.

In the rest of the first section, Mitrović offers an expanded discussion of many of the ideas he has laid out in his own introduction, within the context of statements made in Vignola's introduction. He contrasts Vignola's formalism with the approaches of Filarete, Alberti, Barbaro, and Cesariano. He discusses the concept of symmetry, originating with Vitruvius, which "implies a preference for ratios between whole numbers and precludes the use of incommensurable ratios" [Mitrović 1999: 88]. This leads to a discussion of the significance 
of music - in the larger sense that we might today call harmony - in Renaissance architectural theory. Quoting a pertinent passage from Vignola’s introduction, Mitrović deduces:

Both the decision to rely on commensurable ratios and Vignola's formulation of the canon are thus empirically derived on the basis of common judgment. Musical theory is there only to confirm Vignola's empirical observations [of Roman ruins] [Mitrović 1999: 89].

Once again, this underscores Vignola's formal approach. Mitrović ends the section with a discussion of optical corrections, since it is mentioned in Vignola's introduction. I shall return to this issue when discussing entasis below.

Vignola's plate of "The Five Orders" is the subject of the second section. Mitrović first comments further on the controversy surrounding the authenticity of this plate. He then analyzes the evolution of the use of the term ordine (orders), concluding that Vignola's and Palladio's use of the term was instrumental in its gaining wide acceptance, and describes the formal approach of Vignola within this context.

I must make an aside to point out that, while I completely agree with the overall sense of Mitrović's analysis regarding Vignola's formalism, there is one area where I think he neglects an important point. To make this point, let us return to Mitrović's own introduction, where he contends:

The significance of [Vignola's formalism] becomes obvious if we take into account that meanings cannot be inherent to objects but must be culturally derived, based on convention and mutable as the culture changes. At the same time, a classical architectural theory must explain the uses and sizes of the elements of the orders in a way that leaves no room for relativism in their use - it must be canonical. But if the correct use of the elements of the orders depends on the meanings we attach to themand since meanings are always relative to the system of interpretation - then the use of the classical elements would be relative to the system of interpretation as well. The idea of a canon would become impossible. From this point of view, Vignolas formalism and his reluctance to rely on arguments based on the ascription of meanings to architectural shapes seem well justified. Formalism here implies that the aesthetic sensation humans derive from a building is based upon the contemplation of the shape of the building regardless of the meanings associated with the shape [Mitrović 1999: 18].

I would contend that there is meaning inherent in Vignola's formalism: the meaning is in the mathematics! Why does meaning have to be musical, or anthropomorphic, or architectonic, to be considered relevant? The use of geometry - symmetries, proportional systems, even specific geometric constructions - itself imbues architecture with meaning. Moreover, this is universal, immutable meaning. I believe that this was one of Vignola's (and Alberti's, and Palladio's) core beliefs.

The rest of the commentary, except for the last section on entasis, comprises a thorough comparison of Vignola's treatise with those of Vitruvius, Alberti, Serlio, Barbaro, Palladio and 
Scamozzi with respect to their specifications for the dimensions of the elements of the orders. This is the heart of the commentary and comprises sections on "Intercolumniation", "Tuscan Order", "Doric Order", "Ionic Order", "Corinthian and Composite Orders", and "Attic Base". Pertinent plates from Palladio's I quattro libri dell'architettura are supplied for convenience. Most importantly, however, Mitrović offers over a dozen tables detailing and comparing the ratios specified for all of the elements of the different orders by the various Renaissance treatise writers. Within the text of the commentary, he explains the most omportant relationships exhibited in the data. Of course, he also offers insightful commentary specific to Vignola's canon in these sections. Mitrović's statistics and analysis really have to be seen to be fully appreciated! [see note]

This reviewer would like to have seen a slightly expanded last section, "Entasis". For example, let us return to the issue of optical correction from the first section of the commentary, where Mitrović states, "Vignola's argument is that corrections should be made where the eye cheats us, but that the canon should specify which proportions we want to be perceived" [Mitrović 1999: 89]. Clearly, given the fact that Vignola includes entasis in his treatise, he feels it is an example of one of the optical corrections that should be made. I would contend that, in the entasis construction of Vignola's own invention, he has specified a solution governing what he wants to be perceived.

I would suggest the possibility that Vignola addressed the problem of entasis as a sort of historical and geometric puzzle. Historically, entasis was an accepted tradition, and the standard approach was to diminish the diameter of the column from one-third of its height upwards. I would speculate that Vignola desired to include this historically accepted position (one-third of the way up the column) in his own construction. I would further speculate that Vignola made the observation that this position would correspond roughly to eye level, at least for columns between, say, 15 and 20 feet. Taking this position as a theoretical eye level, then, one natural geometric solution would be to make the following stipulation. As the eye extends its gaze up or down the column, it should perceive, in each direction, the same diameter where the line of sight intersects through the column. Although this is speculation on my part, this appears to be what Vignola's construction accomplishes.

\section{Conclusion}

In many senses, successive English translations of the Canon strayed further and further from Vignola's original treatise as time progressed. More and more auxiliary illustrations were added, the use of the first person was dropped after the first two English translations, and the last three were based not on the original but on a French translation. Mitrović breaks this pattern by taking Vignola's original as his source. He takes advantage of modern technology to offer high-quality reproductions of the original plates. He preserves the first person and the overall sense of original without being slavish to Vignola's cumbersome sentence structure, thereby providing a practical and usable canon for architects and students of architecture. He supplies footnotes where further explanation of the translation is required, and he offers useful background information and exploration in his preface and introduction. Most importantly, he includes a wealth of thorough research and insightful analysis in his commentary. As for my speculation on Vignola's own 
construction for column entasis, the fact that I would include such speculation in the commentary suggests that I would not be the right person for the task. Given the translation and commentary as it stands, Mitrović was clearly the right person.

First published in the NNJ online April 2000

\section{References}

Boyer, Abel and Joseph Moxon, Trans. 1703. The theory and practice of architecture, or Vitruvius and Vignola abridg'd. London: R. Wellington. [The Polifilo chronology lists the publication date as 1702.]

Casotti, Maria Walcher. 1985. Le edizioni della Regola. In Trattati by Pietro Cataneo and Giacomo Barozzi da Vignola. Milan: Edizioni il Polifilo.

Esquié, Pierre and William Robert Powell, Trans. 1921. Vignola: An elementary treatise on architecture comprising the complete study of the five orders. Cleveland: J. H. Jansen. Preface.

Juglaris, Tommaso and Warren Locke, Trans. 1889. The five orders of architecture. Boston: Berwick \& Smith.

Kimball, T. R. Trans. 1891. Practical elementary treatise on architecture, or study of the five orders according to Giacomo Barozzi da Vignola. Boston: Bates \& Guild.

Leeke, John Leeke, Trans. 1669. The regular architect, or the general rule of the five orders of architecture of $M$. Giacomo Barozzio da Vignola. London: R. Reynolds and W. Sherwin, 1669.

Leveil, J. A. 1857. Traité élémentaire praticque d'architecture, ou étude des cinq orders d'après Jacques Barozzio de Vignole. Paris.

Moxon, Joseph, trans. 1655. Vignola. London: J. Moxon.

Mitrović, Branko, Trans. 1999. Canon of the Five Orders of Architecture by Giacomo Barozzi Da Vignola. New York: Acanthus Press.

Sayer, Robert. 1761. Vignola revived. London: R. Sayer.

Tuckerman, Arthur Lyman, Trans. 1891. The five orders of architecture, according to Giacomo Barozzio Vignola, to which are added the Greek orders. New York: Wm. T. Comstock.

Ware, William R. 1901. The American Vignola: A guide to the making of classical architecture. New York: Columbia University.

\section{Note}

An expansion of this analysis can be found in Branko Mitrović, "Palladio's Theory of the Classical Orders in the First Book of I quattro libri dell'architettura," Architectural History 42 (1999), 110-140; the core data from this article is shown in the tables of the present commentary. This reviewer would prefer to see the ratio data given in fractional form rather than decimal form (both are included in the Architectural History article), since proportional relationships are more apparent with fractions. Decimal form may be more suitable for a working handbook, however, and that is what Mitrović desires to provide.

\section{The Reviewer}

Stephen R. Wassell is an Associate Professor of Mathematical Sciences at Sweet Briar College in Virginia (USA). He received a Bachelor of Science degree in Architecture, a Master of Science and a Ph.D. in Mathematics, and a Master of Computer Science, all from the University of Virginia. After publishing several articles in his doctoral research area, mathematical physics, he is now studying the relationships between architecture and mathematics. $\mathrm{He}$ has designed and taught a course entitled Math in Architecture at Sweet Briar. He is the author of "The Mathematics of Palladio's Villas", Nexus II: Architecture and Mathematics, Kim Williams, ed. (Fucecchio: Edizioni dell'Erba, 1998), pp. 173-186. He was the leader of the workshop tour of Palladio's villas that followed Nexus '98 and published "The Mathematics of Palladio's Villas: Workshop '98", NNJ 1, pp. 121-128. At Nexus 2000 he presented "Architecture and Mathematics Before the Quattrocento: A Context for Understanding Renaissance Architecture", Nexus III: Architecture and Mathematics, Kim Williams, ed. (Pisa: Pacini Editore, 2000), pp. 157-168. 